Supporting Information

\title{
Identification of Catalytic Active Sites in Nitrogen-Doped Carbon for Electrocatalytic Dechlorination of \\ 1,2-Dichloroethane
}

Guoqiang Gan, $\uparrow$ Xinyong Li, ${ }^{*}, \uparrow \dagger$ Liang Wang, $\uparrow$ Shiying Fan, $, \uparrow \mathrm{Ji} \mathrm{Li}, \dagger$ Feng Liang,

$$
\dagger \text { and Aicheng Chen*† }
$$

$\uparrow$ State Key Laboratory of Fine Chemicals, Key Laboratory of Industrial Ecology and Environmental Engineering (MOE), School of Environmental Science and Technology, Dalian University of Technology, Dalian 116024, China

$\$$ Electrochemical Technology Center, Department of Chemistry, University of Guelph, 50 Stone Road East, Guelph, Ontario N1G 2W1, Canada

*E-mail: xyli@dlut.edu.cn; Phone/Fax: +86 41184706658 (X.L.).

*E-mail: aicheng@uoguelph.ca (A.C.). 


\section{Table of Contents}

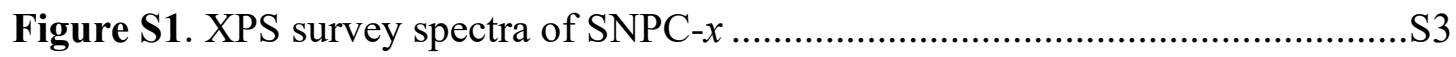

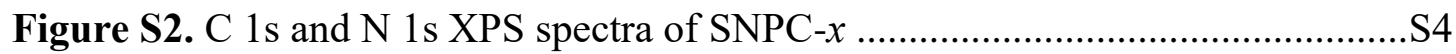

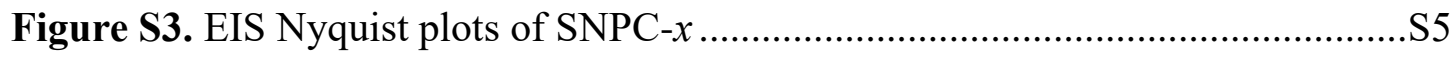

Figure S4. GC-MS spectra of the final gas products .................................................. 6

Figure S5. Stability and reusability of SNPC-10 ..................................................

Figure S6. In-situ diffuse reflectance FTIR spectra ..............................................S8

Figure S7. Temperature-programmed reduction profiles of SNPC-10 ….................S9

Figure S8. Corresponding potentiostatic current density of SNPC-10-T ….............S10

Figure S9. Dependence of the $\mathrm{C}_{2} \mathrm{H}_{2}$ partial current density on the normalized contents of different $\mathrm{N}$ dopants

Figure S10. Evolution amount of $\mathrm{C}_{2} \mathrm{H}_{2}$ with respect to the content of Oxidized $\mathrm{N}$ (active site) for SNPC- $x$ and SNPC-10-T $\mathrm{S} 12$

Figure S11. Geometry structure of N-doped carbon materials S13

Figure S12. Geometry structures of the ${ }^{*} \mathrm{CH}_{2} \mathrm{ClCH}_{2}$ step on $\mathrm{N}$ dopants................S14

Figure S13. Calculated DOS plots of N-doped carbon materials ...........................S15

Table S1 Pore structure parameters of the original BC and SNPCs........................S16

Table S2 Equivalent circuit model corresponding to the Nyquist plots ...................S16

Table S3 Contents of different N species in SNPC- $x$ and $\mathrm{H}_{2}$ treated SNPC-10-T ....S16

Table S4 Correlation coefficients ( $r$ ) of regression equation. S16

Table S5 Normalized contents of different N species in SNPC- $x$ and SNPC- $x$-T ....S17

Table S6 Correlation coefficients ( $r$ ) of regression equation between dechlorination activity and the normalized contents of different $\mathrm{N}$ dopants S17 


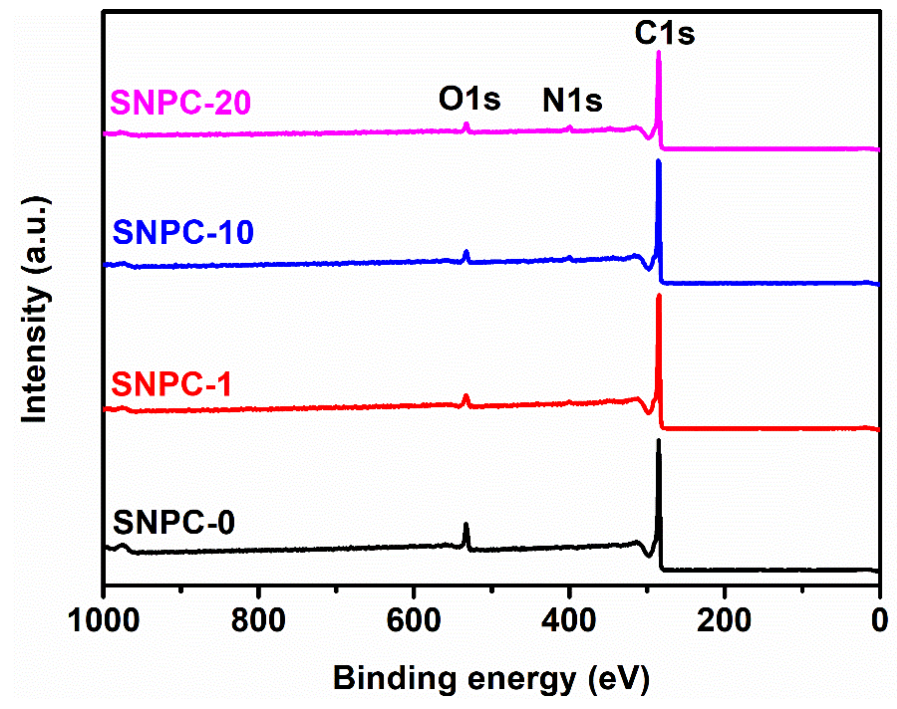

Figure S1. XPS survey spectra of SNPC- $x$. 

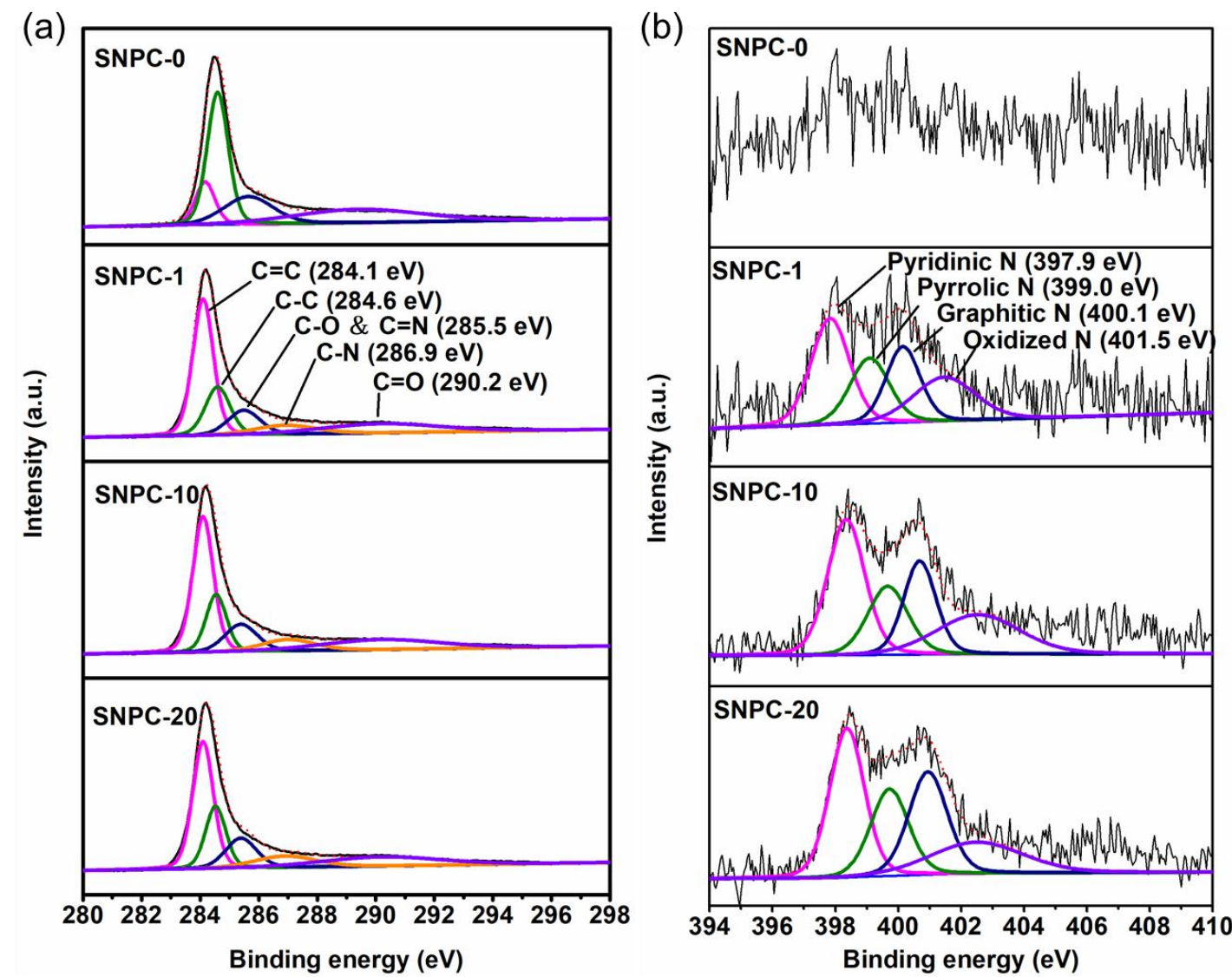

Figure S2. (a) C 1s and (b) N 1s XPS spectra of SNPC- $x$. 


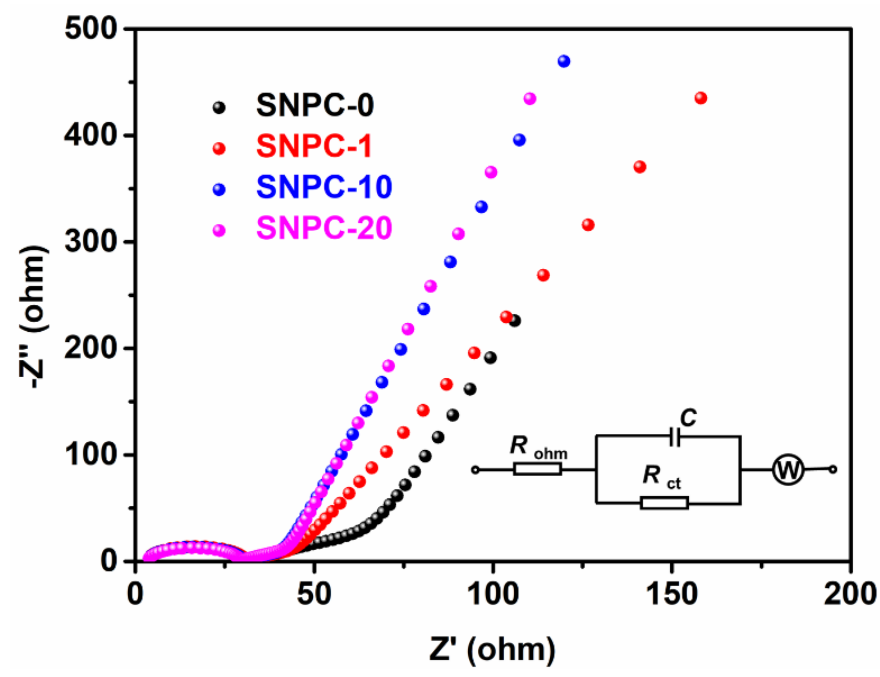

Figure S3. Electrochemical impedance spectroscopic (EIS) Nyquist plots of SNPC- $x$. The inset is the equivalent circuit. 
(a)

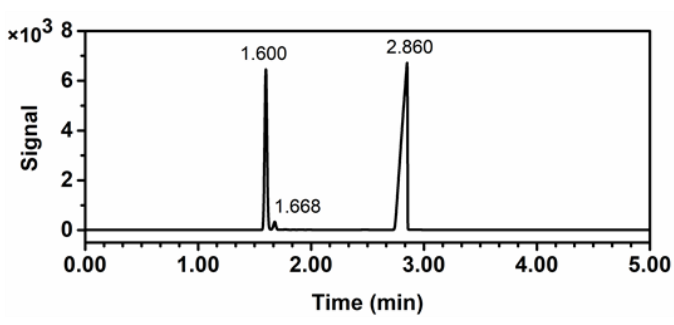

(c)

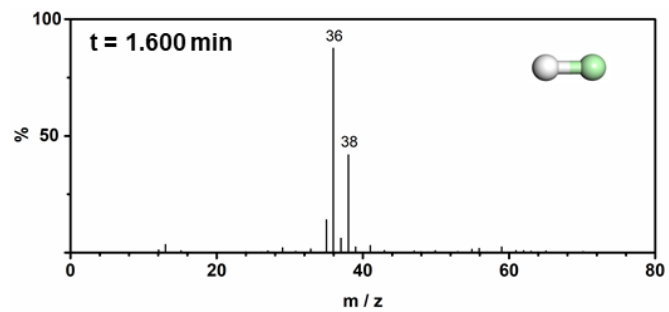

(b)

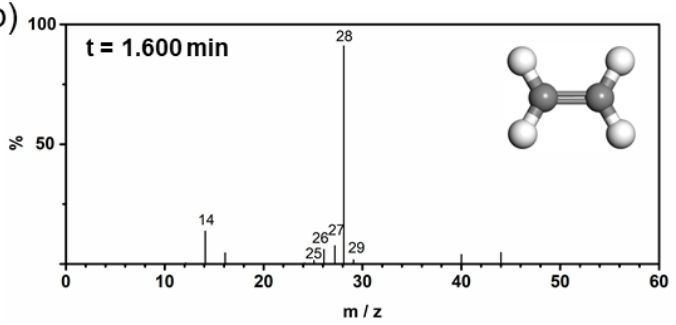

(d)

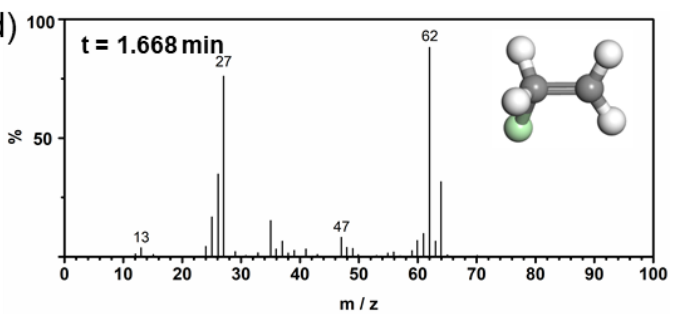

Figure S4. GC-MS spectra of the final gas products: (a) total ions chromatogram; and mass spectra of (b) ethylene, (c) hydrogen chloride, and (d) vinyl chloride. 

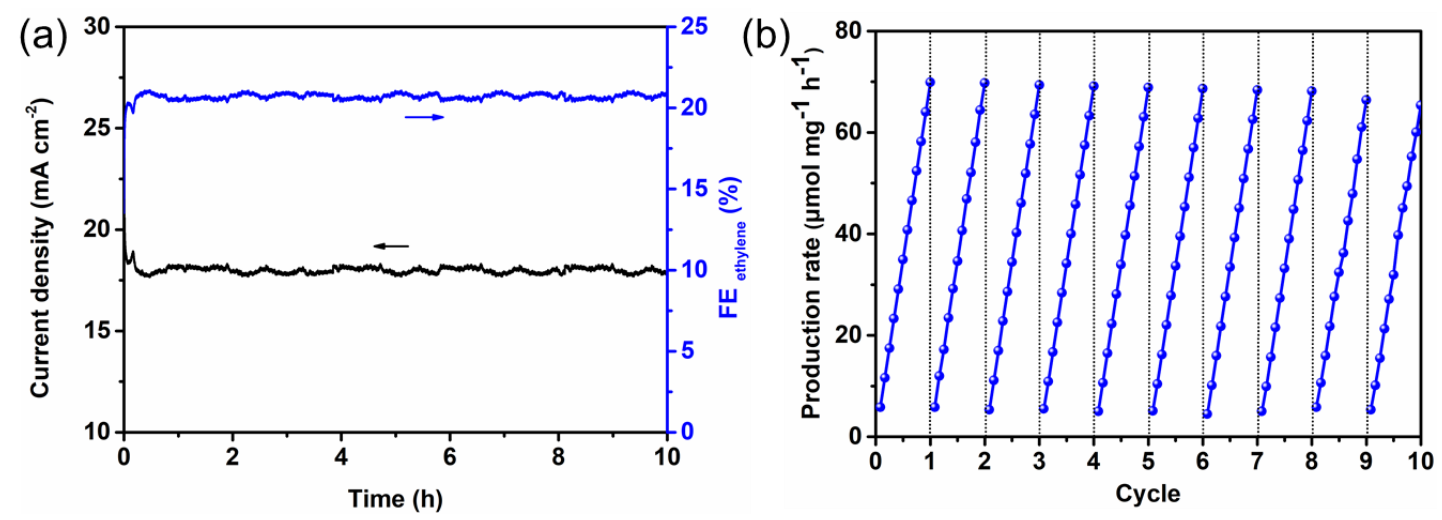

Figure S5. Stability and reusability of SNPC-10: (a) Long-term electrochemical test, showing the high stability of the current density and the Faradaic efficiency of ethylene; (b) Reusability of SNPC-10 during 10 consecutive cycles. 

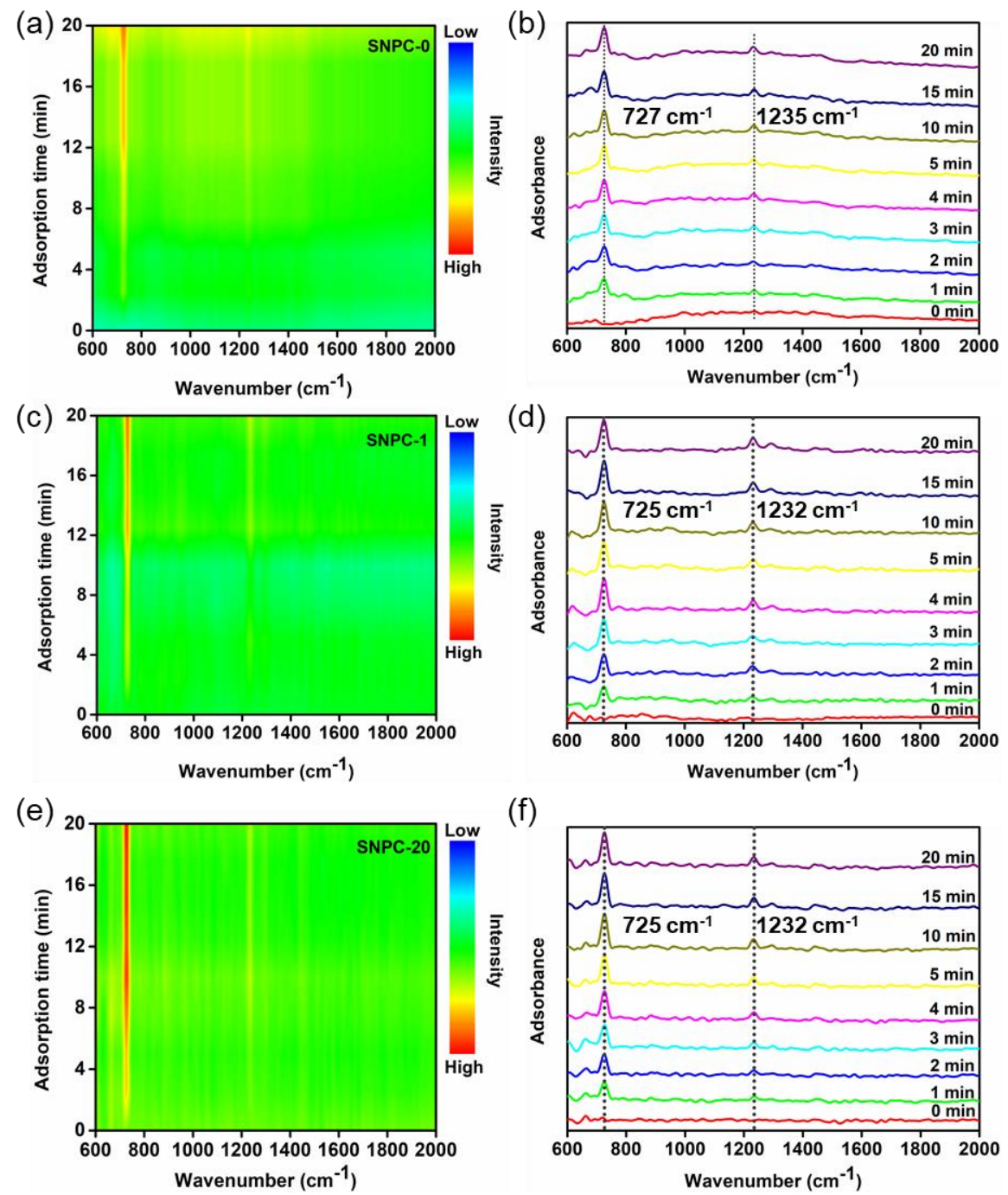

Figure S6. In situ diffuse reflectance FTIR spectra of the adsorption process for gaseous DCE over the SNPC-0, SNPC-1 and SNPC-20 samples in the corresponding time-domain IR spectra. 


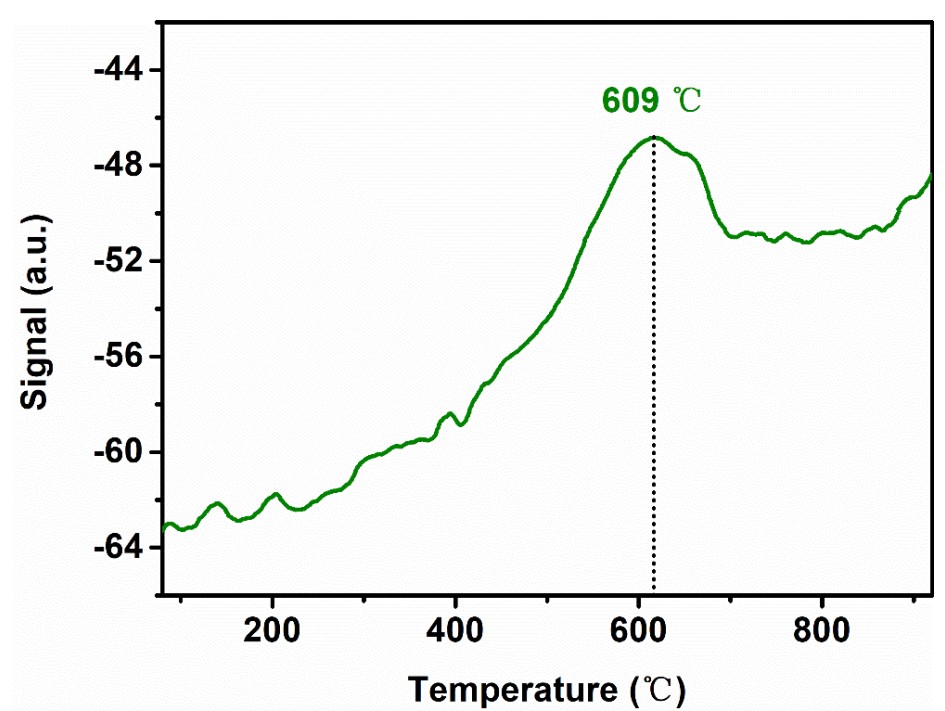

Figure S7. Temperature-programmed reduction profile of SNPC-10. 


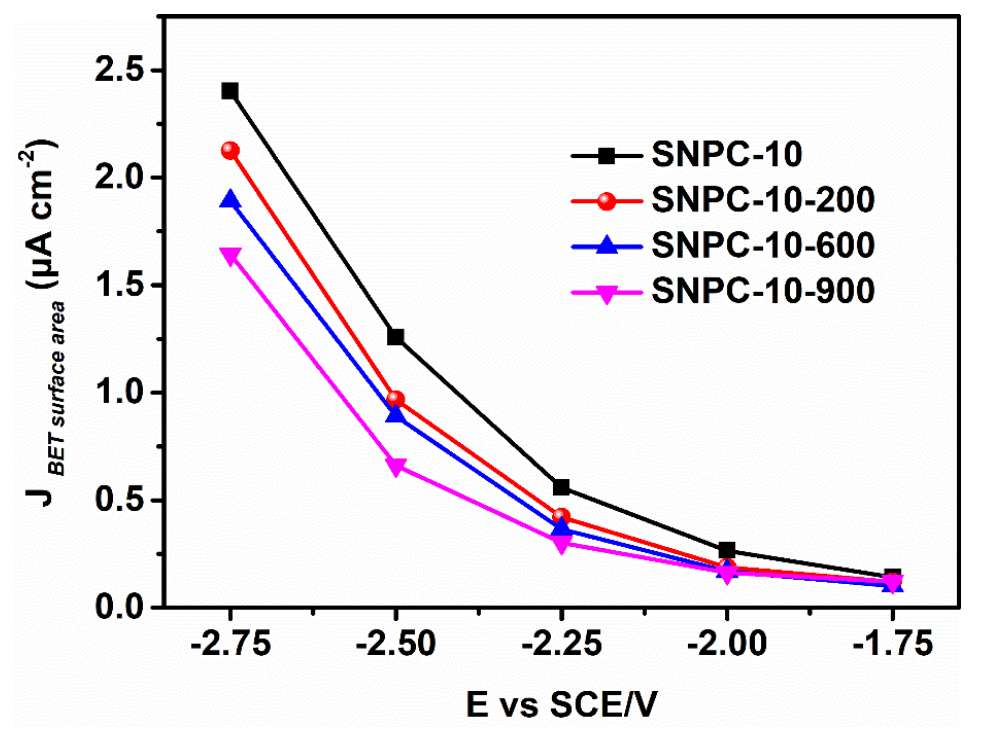

Figure S8. Corresponding potentiostatic current density of SNPC-10 and SNPC-10-T. 

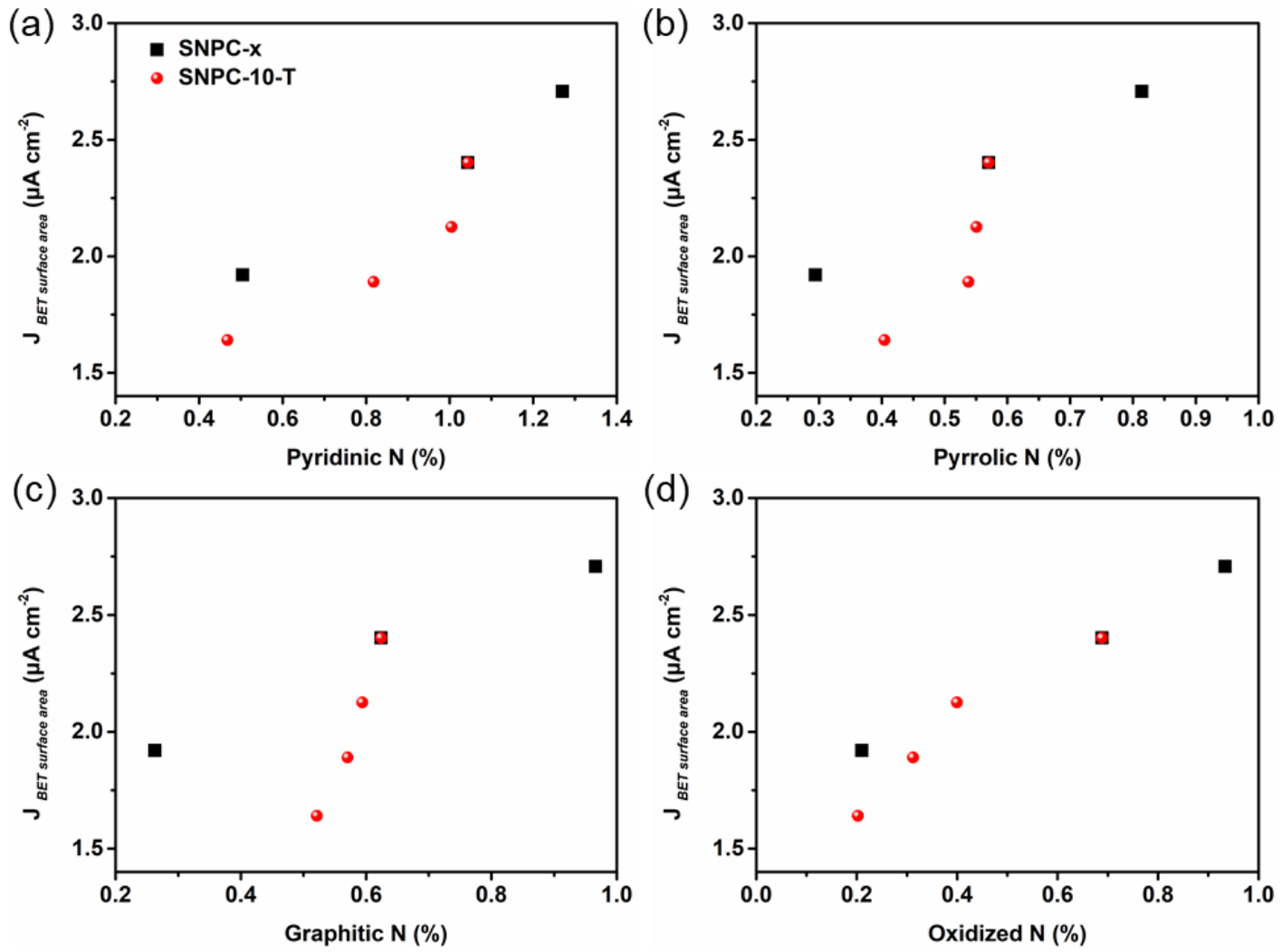

Figure S9. Dependence of the $\mathrm{C}_{2} \mathrm{H}_{2}$ partial current density on the normalized contents of different $\mathrm{N}$ dopants at -2.75 V (vs SCE) for SNPC- $x$ and SNPC-10-T: (a) Pyridinic N; (b) Pyrrolic N; (c) Graphitic N; and (d) Oxidized N. The black squares represent SNPC-1, SNPC-10 and SNPC-20 from left to right, respectively. The red balls represent SNPC-10-900, SNPC-10-600, SNPC-10-200, and SNPC-10 from left to right, respectively. 


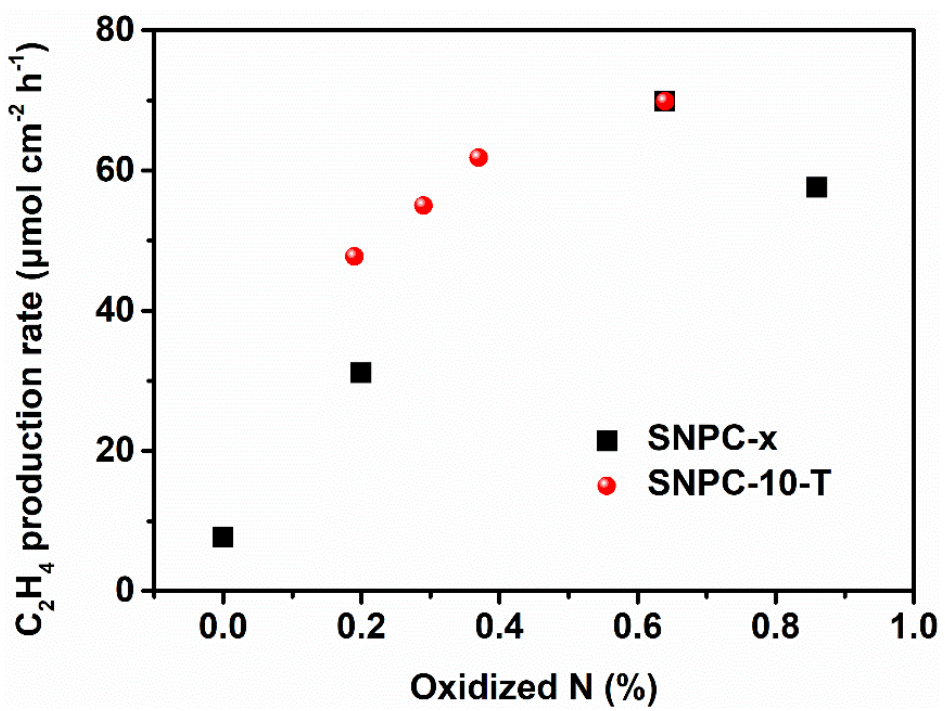

Figure S10. Production rate of $\mathrm{C}_{2} \mathrm{H}_{2}$ with respect to the content of Oxidized N (active site) for SNPC- $x$ and SNPC-10-T. The black squares represent SNPC-0, SNPC-1, SNPC-10 and SNPC-20 from left to right, respectively. The red balls represent SNPC-10-900, SNPC-10-600, SNPC-10-200, and SNPC-10 from left to right, respectively. 


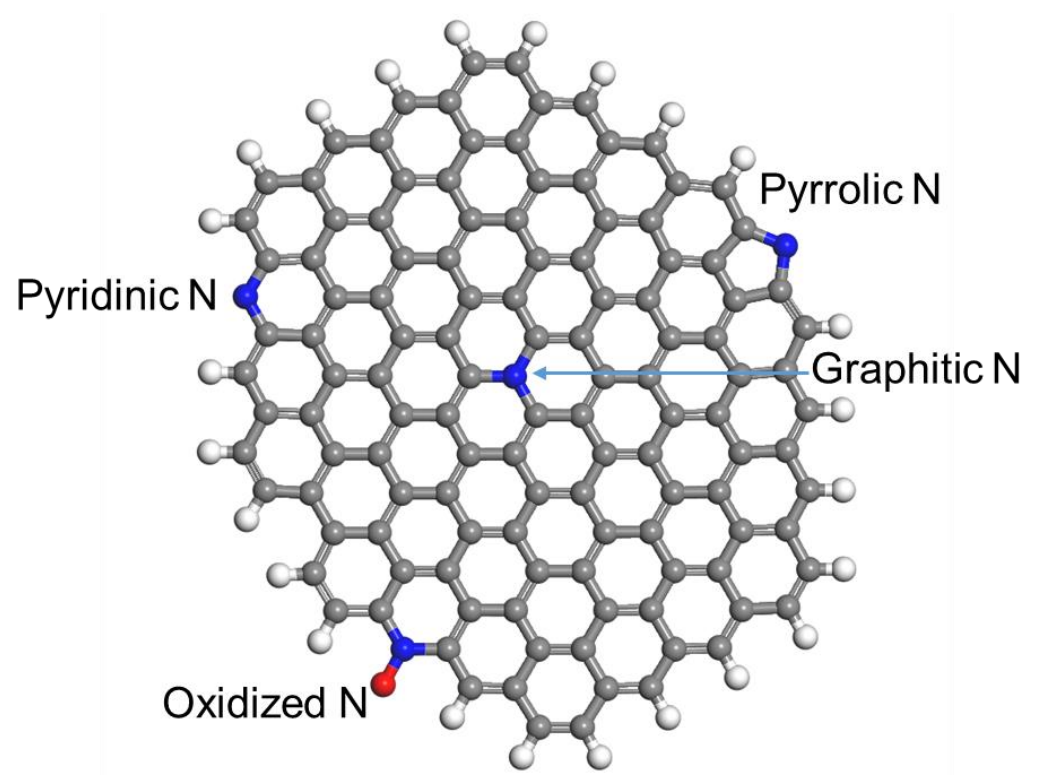

Figure S11. Geometry structure of N-doped carbon materials at the atomic level from the first-principle. 
(a)

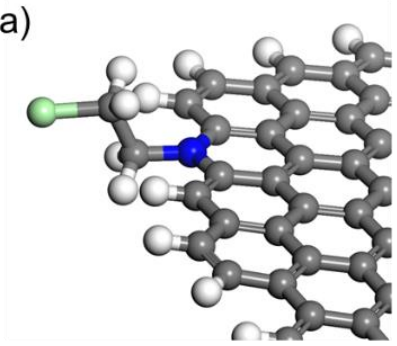

(c)

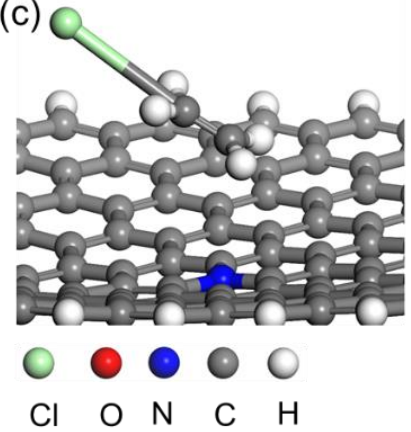

(b)

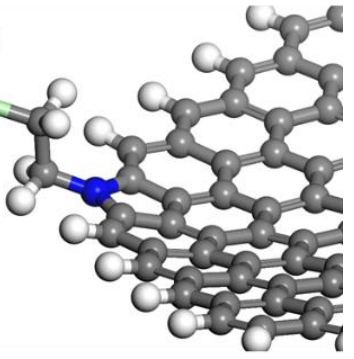

(d)

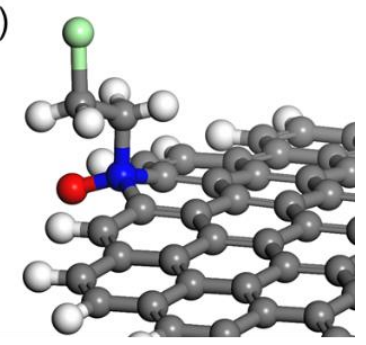

Figure S12. Geometry structures of $*_{-} \mathrm{CH}_{2} \mathrm{ClCH}_{2}$ step on (a) pyridinic $\mathrm{N}$, (b) pyrrolic $\mathrm{N}$, (c) graphitic $\mathrm{N}$ and (d) oxidized $\mathrm{N}$. 


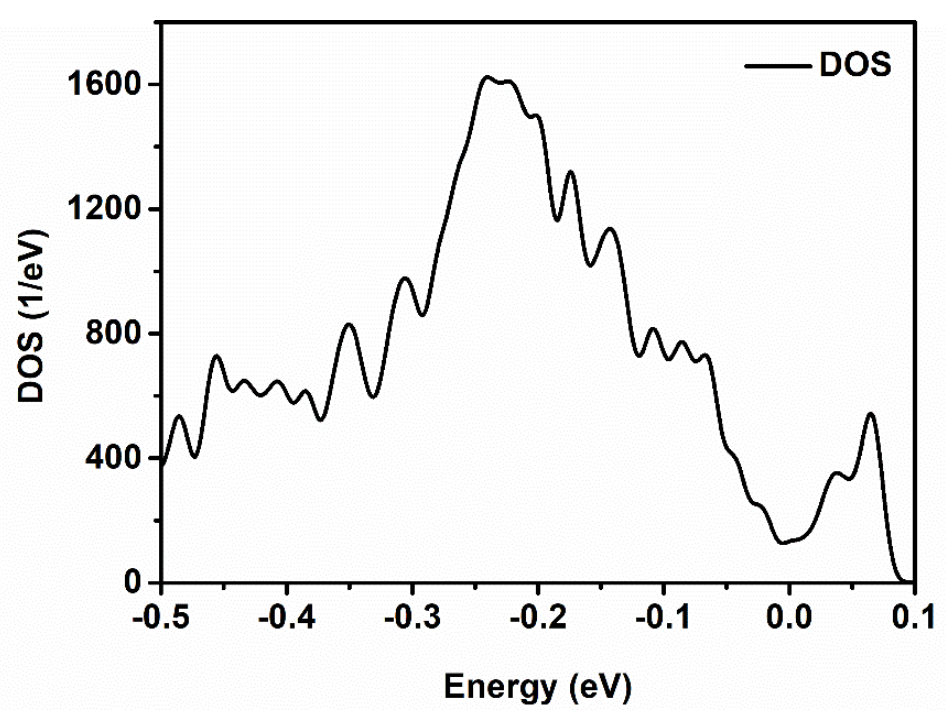

Figure S13. The calculated DOS plots of N-doped carbon materials. 
Table S1 Pore structure parameters of the original BC and SNPCs.

\begin{tabular}{cccccc}
\hline \multirow{2}{*}{ Samples } & \multicolumn{5}{c}{ Textual Properties } \\
\cline { 2 - 6 } & $\mathrm{S}_{\mathrm{BET}}\left(\mathrm{m}^{2} \mathrm{~g}^{-1}\right)$ & $\mathrm{S}_{\text {Micro }}\left(\mathrm{m}^{2} \mathrm{~g}^{-1}\right)$ & $\mathrm{V}_{\mathrm{T}}\left(\mathrm{cm}^{3} \mathrm{~g}^{-1}\right)$ & $\mathrm{V}_{\text {Micro }}\left(\mathrm{cm}^{3} \mathrm{~g}^{-1}\right)$ & $\mathrm{V}_{\text {Micro }} / \mathrm{V}_{\mathrm{T}}$ \\
\hline SNPC-0 & 1161 & 954 & 0.647 & 0.425 & 0.66 \\
SNPC-1 & 1236 & 1001 & 0.673 & 0.455 & 0.68 \\
SNPC-10 & 1250 & 1021 & 0.674 & 0.465 & 0.69 \\
SNPC-20 & 1133 & 941 & 0.617 & 0.428 & 0.69 \\
\hline
\end{tabular}

Table S2 Equivalent circuit model corresponding to the Nyquist plots of the as-prepared SNPC- $x$ samples.

\begin{tabular}{ccccc}
\hline Samples & $R_{\mathrm{ohm}}\left(\Omega \mathrm{cm}^{-2}\right)$ & $R_{\mathrm{ct}}\left(\mathrm{G} \Omega \mathrm{cm}^{-2}\right)$ & $\left.\mathrm{C}(\mathrm{mF} \mathrm{cm})^{-2}\right)$ & $\mathrm{W}\left(\mathrm{S} \mathrm{Sec}^{5} \mathrm{~cm}^{-2}\right)$ \\
\hline SNPC-0 & $32.60 \pm 1.11$ & $326 \pm 1.10$ & $0.01 \pm 0.00001$ & $0.050 \pm 0.009$ \\
SNPC-1 & $30.57 \pm 1.34$ & $2.681 \pm 0.03$ & $2.00 \pm 0.30$ & $0.163 \pm 0.026$ \\
SNPC-10 & $29.77 \pm 1.30$ & $1.681 \pm 0.02$ & $13.60 \pm 2.00$ & $0.201 \pm 0.040$ \\
SNPC-20 & $28.86 \pm 1.44$ & $1.530 \pm 0.01$ & $18.40 \pm 3.00$ & $0.220 \pm 0.005$ \\
\hline
\end{tabular}

Table S3 Contents of different N in SNPC- $x$ and $\mathrm{H}_{2}$ treated SNPC-10-T

\begin{tabular}{|c|c|c|c|c|c|}
\hline \multirow{2}{*}{ Samples } & \multirow{2}{*}{$\begin{array}{c}\text { Total N } \\
\text { contents } \\
(\text { at. \%) }\end{array}$} & \multicolumn{4}{|c|}{ Individual N Contents (at. \%) } \\
\hline & & Pyridinic N & Pyrrolic N & Graphitic N & Oxidized N \\
\hline SNPC-0 & - & - & - & - & - \\
\hline SNPC-1 & 1.21 & 0.48 & 0.28 & 0.25 & 0.20 \\
\hline SNPC-10 & 2.72 & 0.97 & 0.53 & 0.58 & 0.64 \\
\hline SNPC-20 & 3.67 & 1.17 & 0.75 & 0.89 & 0.86 \\
\hline SNPC- $10-200^{\circ} \mathrm{C}$ & 2.36 & 0.93 & 0.51 & 0.55 & 0.37 \\
\hline SNPC- $10-600^{\circ} \mathrm{C}$ & 2.08 & 0.76 & 0.50 & 0.53 & 0.29 \\
\hline SNPC- $10-900^{\circ} \mathrm{C}$ & 1.50 & 0.44 & 0.38 & 0.49 & 0.19 \\
\hline
\end{tabular}

Table S4 Correlation coefficients $(r)$ of regression equation between dechlorination activity and the contents of different $\mathrm{N}$ dopants

\begin{tabular}{ccccc}
\hline & Pyridinic N & Pyrrolic N & Graphitic N & Oxidized N \\
\hline$r$ of SNPC- $x$ & 0.9939 & 0.9958 & 0.9939 & 0.9980 \\
$r$ of SNPC- $x$ - $\mathrm{T}$ & 0.9069 & 0.8680 & 0.9346 & 0.9694 \\
$r$ of all samples & 0.8967 & 0.8308 & 0.7708 & 0.9706 \\
\hline
\end{tabular}


Table S5 Normalized contents of different N in SNPC- $x$ and $\mathrm{H}_{2}$ treated SNPC- $x$-T, where the carbon is "constant" between samples.

\begin{tabular}{|c|c|c|c|c|c|}
\hline \multirow{2}{*}{ Samples } & \multirow{2}{*}{$\begin{array}{l}\text { Total N } \\
\text { contents } \\
\text { (at. \%) }\end{array}$} & \multicolumn{4}{|c|}{ Individual N Contents (at. \%) } \\
\hline & & Pyridinic N & Pyrrolic N & Graphitic N & Oxidized $\mathrm{N}$ \\
\hline SNPC-0 & - & - & - & - & - \\
\hline SNPC-1 & 1.27 & 0.50 & 0.29 & 0.26 & 0.21 \\
\hline SNPC-10 & 2.93 & 1.04 & 0.57 & 0.62 & 0.69 \\
\hline SNPC-20 & 3.98 & 1.27 & 0.81 & 0.97 & 0.93 \\
\hline SNPC- $10-200^{\circ} \mathrm{C}$ & 2.55 & 1.00 & 0.55 & 0.59 & 0.40 \\
\hline SNPC- $10-600^{\circ} \mathrm{C}$ & 2.24 & 0.82 & 0.54 & 0.57 & 0.31 \\
\hline SNPC- $10-900^{\circ} \mathrm{C}$ & 1.60 & 0.47 & 0.40 & 0.52 & 0.20 \\
\hline
\end{tabular}

Table S6 Correlation coefficients $(r)$ of regression equation between dechlorination activity and the normalized contents of different $\mathrm{N}$ dopants

\begin{tabular}{ccccc}
\hline & Pyridinic N & Pyrrolic N & Graphitic N & Oxidized N \\
\hline$r$ of SNPC- $x$ & 0.9946 & 0.9956 & 0.9936 & 0.9984 \\
$r$ of SNPC- $x$ - $\mathrm{T}$ & 0.9315 & 0.8663 & 0.9358 & 0.9671 \\
$r$ of all samples & 0.9154 & 0.8362 & 0.7640 & 0.9689 \\
\hline
\end{tabular}

